\title{
Scientific communication in nursing
}

Francisco Carlos Félix Lana ${ }^{a}$
D0l: http://dx.doi.org/10.1590/19831447.2015.03.58243

"Scientific communication can be understood as a set of consensually and socially shared efforts, facilities, dynamic and complex processes through which scientific knowledge is created, shared and used. These processes also offer the means and conditions for social interaction between members of scientific communities, thereby contributing to the production, dissemination and use of knowledge and, consequently, to the advance of science ${ }^{\prime \prime(1)}$.

New technological possibilities brought by the large-scale introduction of electronic networks into scientific communication and the search to legitimize new forms of online scientific communication triggered a reconfiguration of the communication elements directly affecting the generation, dissemination and use of scientific information.

Based on the institutionalization of science and specialization of knowledge, in the scientific communication process scientific articles (and their vehicle, journals) form the primary framework in the creation of scientific structure by achieving greater efficiency and effectiveness in large-scale knowledge transfer. However, it is important to underscore that scientific articles are currently more of a resource for regulating scientific activities (of researchers and journals) than a universal form of communicating scientific development.

Thus, attention should be given to criticisms of traditional analysis models that afford scientific articles the privilege of examining scientific activity and making inferences about the state of science; that is, "scientific activity cannot be reduced to the production, circulation and consumption of journal articles, much less confuse the quantitative growth in articles with the cognitive development of science.

It is not only about quantifying and verifying data, but attributing meaning to them for better use in science and technology policies, for each specialty or research group, or in broader national and international cultural, political, ideological and economic contexts ${ }^{(2)}$.

Analyzing the scientific communication process in nursing involves: a) mapping information sources (who, what and where); b) identifying the strategies that allow the recovery or acquisition of information (access to the knowledge produced); c) storing or organizing knowledge; d) sharing (means of communication and dissemination) and; e) creation (scientific research) $)^{(1)}$.

It is imperative to understand how each of the abovementioned elements are organized or prioritized in the different institutions that handle the production/creation, systematization and dissemination of knowledge in the field of Nursing. This understanding is vital to the development of strategies that enhance the development of nursing knowledge as a science, thus amplifying its visibility and dissemination to achieve higher levels of influence on health care quality and practices.

In this respect, it is important to strengthen initiatives and strategic actions aimed at developing the field of scientific knowledge in nursing, particularly the BVS Nursing database, REV@ENF jornal portal, Journal Editor's Forum and IberoAmerican Network of Scientific Editing in Nursing, among others.

Efforts should be made to progress to a new framework of nursing themes and terminology to provide bibliographic strategies for the systematization of knowledge and expand information recovery possibilities and its resulting visibility.

Universidade Federal de Minas Gerais (UFMG), Escola de Enfermagem, Belo Horizonte, Minas Gerais, Brasil. 
Efforts should also focus on creating and developing strategies and actions that identify new flows and sharing relationships between researchers, institutions and editors.

Another noteworthy aspect is the quality of scientific communication. The adoption of international consensus for scientific communication by Journals could contribute significantly towards improving communication and dissemination, as well as the desired impact on the field of evidence for the foundation of care.

Finally, the field of scientific communication in nursing should be capable of raising awareness and mobilizing institutions and national and international leaders to build the technical and political sustainability needed to protect and develop the technical and scientific heritage of nursing.

\section{REFERENCES}

1. Leite FCL, Costa SMS. Gestão do conhecimento científico: proposta de um modelo conceitual com base em processos de comunicação científica. Ci Inf [Internet]. 2007 [citado 2015 ago. 28];36(1):92-107. Disponível em: https://www.sct.embrapa.br/publicacoes/FernandoLeite_Cl.pdf

2. Santos RNM, Kobashi NY. Bibliometria, cientometria, infometria: conceitos e aplicações. Pesq Bras Ci Inf. 2009;2(1):155-72. 